\title{
Water pipe network as a heat source for heat pump integrated into a district heating
}

\author{
Piotr Jadwiszczak ${ }^{1}$, and Elżbieta Niemierka ${ }^{1, *}$ \\ ${ }^{1}$ Wroclaw University of Science and Technology, Faculty of Environmental Engineering, \\ Wybrzeże Wyspiańskiego 27, 50-370 Wrocław, Poland
}

\begin{abstract}
The paper will present a technical analysis of the performance of the Heat Pumps (HP) installed in the domestic water pipe network for a big city scale. The HP integration scheme predicts the domestic water flow as a heat source and the district heating as a heat sink. The technical factors which influence on the estimated thermal power and performance of HP unit will be identified. Additionally, the pros and cons of HP operation in water intake will be determined. The analysis will be based on long-term measurement data from Głogów city.
\end{abstract}

\section{Introduction}

The Heat Pump (HP) technology is one of the most dynamically developing branches of Renewable Energy Sources (RES) in heating sector. The HP units, based on thermodynamic refrigeration cycle, use the low grade heat from air, water, geothermal, waste, etc. to generate useful thermal energy and consuming only a small amount of driving energy. The water-to-water HP technology (water source HP) allows to use the water as a low temperature heat source and offers high performance of HP units. The thermal power and performance of water-to-water HP unit depends on two main factors: the flow rate and the temperature of heat source water. Additionally, the heat source water should be available with sufficient quantity and quality, without contaminants, best with constant annual temperature.

\section{The idea}

The city water network seems to be a profitable heat source for water-to-water HP thermal station located on main pipeline near to the drinking water treatment plant (fig. 1). The favorable conditions for HP technology are: large and stable water flow for whole city and fluid without any contaminants. The temperature of heat source water dependents on type of water intake. The water intakes can be divided into surface and groundwater. In surface intakes the raw water temperature varies strongly with the year seasons, which changes the working conditions and reduces HP performance. The groundwater intakes are more advisable for HP due to the stable temperature during the year. To generate useful thermal energy HP unit need to decrease the domestic water temperature only by 1-3 K [1]. After

\footnotetext{
*Corresponding author: elzbieta.niemierka@pwr.edu.pl
} 
that the cooled water will be re-heated in non-insulated underground domestic water distribution network, so the cooling phenomenon will not be noticeable by domestic water users. Water-to-water HP at seasonal efficiency $\mathrm{SCOP}=5,2$ by cooling all domestic water in Poland [2] only by $1 \mathrm{~K}$ can generate about $54 \mathrm{PJ}$ of useful renewable heat per year, representing almost $10 \%$ of total heat demand in polish residential heating sector [3]. This is a huge available energy potential in heating sector, which can help lower the building's utility bills.

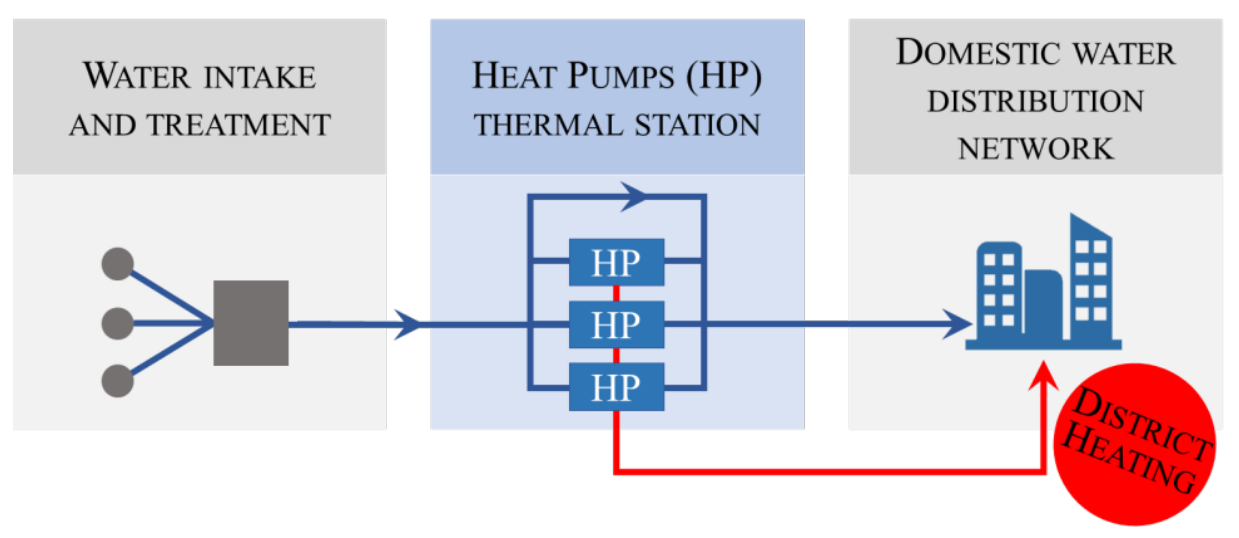

Fig. 1. Water source HP thermal station in domestic water distribution network.

\section{Pros \& cons list}

The domestic water network can be used as a heat source both for small and large scale HP units [4]. The assessing the pros and cons of HP integration in water network must be taken into account (Tab. 1). Pros \& cons lists are a quick and easy way to a decision-making and a risk analyse. The pros are related to renewable energy, economics and ecology. The cons are connected with ecological risk, investment and technical issues. It should be noted that economic and ecological factors are on both sides of the list. Low operational cost vs large investment and renewable heat vs risk of water contamination. The proper choice of technical solution and good design allow minimizing issues from the cons list.

Table 1. Pros \& cons list.

\begin{tabular}{|c|c|}
\hline Pros & Cons \\
\hline $\begin{array}{l}\text { - HP units generate the renewable heat from } \\
\text { domestic water network } \\
\text { - water-to-water HP technology offers higher } \\
\text { performance factors }\end{array}$ & $\begin{array}{l}\text { - risk of water contamination } \\
\text { - large investment cost } \\
\text { - risk of emergency shutdowns of HP units } \\
\text { due to low water flow }\end{array}$ \\
\hline Pros & Cons \\
\hline $\begin{array}{l}\text { - water networks are large, widely available } \\
\text { and favorable heat source for HP technology } \\
\text { - the cooled domestic water will be re-heated } \\
\text { in underground network } \\
\text { - the water temperature drop will not be } \\
\text { noticeable by users' }\end{array}$ & $\begin{array}{l}\text { - availability of heat sink } \\
\text { - incompatibility parameters of heat sink }\end{array}$ \\
\hline
\end{tabular}




\section{The city Głogów case study}

To illustrate the potential of HP integration into domestic water network the technical and the energy analysis was made on the case of the real water network in city Głogów. The goal is the properly selection of HP units and their parameters to the water network conditions and to supply the maximum amount of renewable heat from the HP thermal station.

The mathematical model was developed to calculate the Coefficient Of Performance (COP), the Seasonal Coefficient Of Performance (SCOP), supplied heat and driving energy consumption of HP units. The model includes: the measured intake water flow and temperature, the domestic water temperature drop (water cooling), the COP characteristics of HP units, the permitted domestic water flows ranges for HP units, the risk of HP units emergency shutdowns caused by low water flow and the weather data.

The study was based on measurement data of intake water flow in water network in city Głogów. The Głogłów city with a population of over 68000 people has the city scale water network and the district heating systems. The database contains hourly flows and temperatures of intake water for years 2014, 2015 and 2016. The source of water is the groundwater intakes (drilled wheels) with a depth of 40 to $60 \mathrm{~m} \mathrm{[5]} \mathrm{and} \mathrm{steady} \mathrm{temperature}$ in the year around $10,8^{\circ} \mathrm{C}$. The water demand in the city determines the rate and variability of intake water flow. Figures 3, 4 and 5 and table 2 show the statistics of intake water flows for the city of Głogów based on measurement data.

On this basis the number and size of water-to-water, electrically driven HP units were chosen. It should be noted that the large scale one-stage compression HP units can work only in well-defined water flows range, eg. from 50 to $120 \%$ of its nominal flow. An exceeding this range causes an emergency shutdown of HP unit. The shutdowns and startups of large scale HP units are the time- and energy-consuming processes. Restarting involves and causes energy losses due to reduced heat production or its total absence during this procedure. For these reasons the HP thermal station design is based on the maximum use of water flow and minimum the risk of HP emergency shutdown. The next factors that should be considered during the selection of HP units are their quantity, thermal power and performance. Consequently, the proper design of HP thermal station requires detailed intake water flows analysis based on measured data.

Table 2. The statistics of water intake flows for the city of Głogów.

\begin{tabular}{|c|c|c|c|}
\hline & Year 2014 & Year 2015 & Year 2016 \\
\hline Water intake flow range, m3/h & $219-492$ & $206-500$ & $251-499$ \\
\hline Median, m3/h & 363 & 345 & 350 \\
\hline Standard deviation, m3/h & 38 & 35 & 28 \\
\hline
\end{tabular}




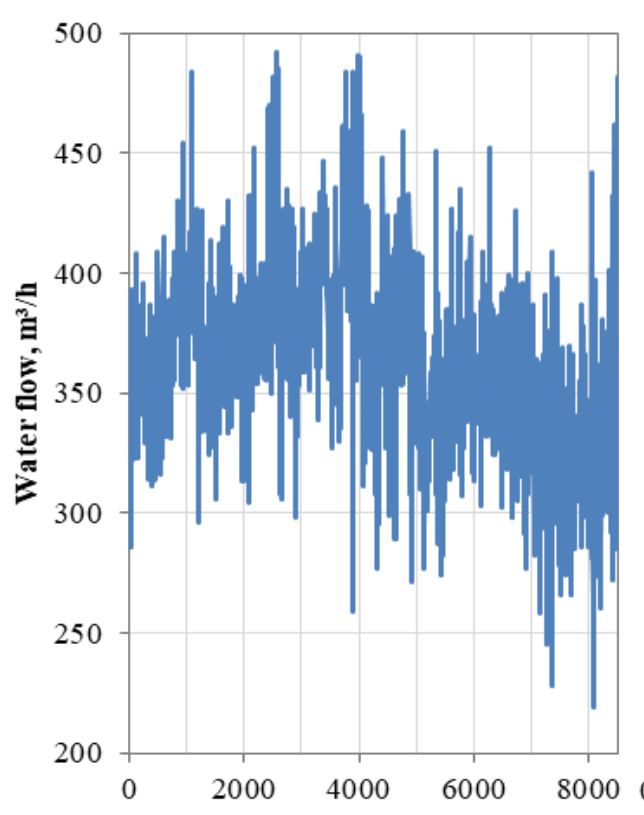

Time, h

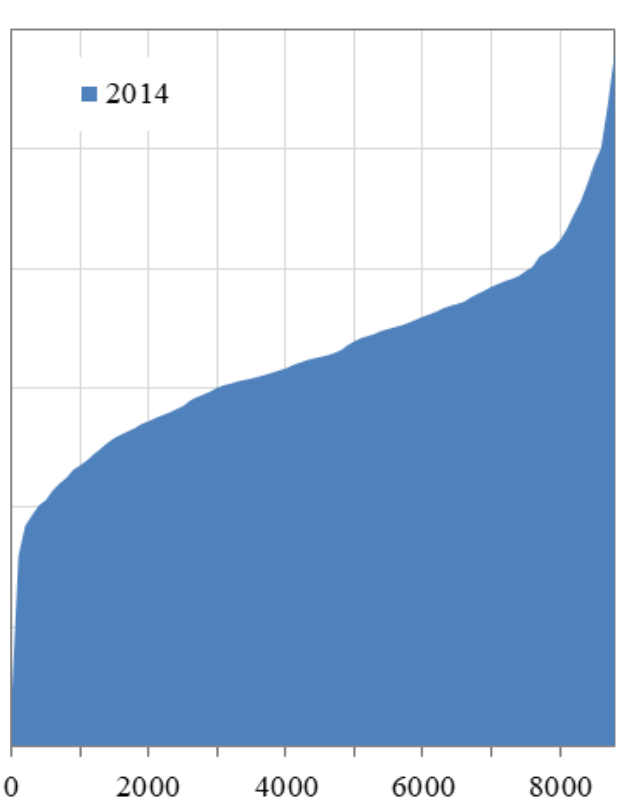

Cumulative frequency, $h$

Fig. 2. Intake water flows ratio and its cumulative frequency in year 2014.
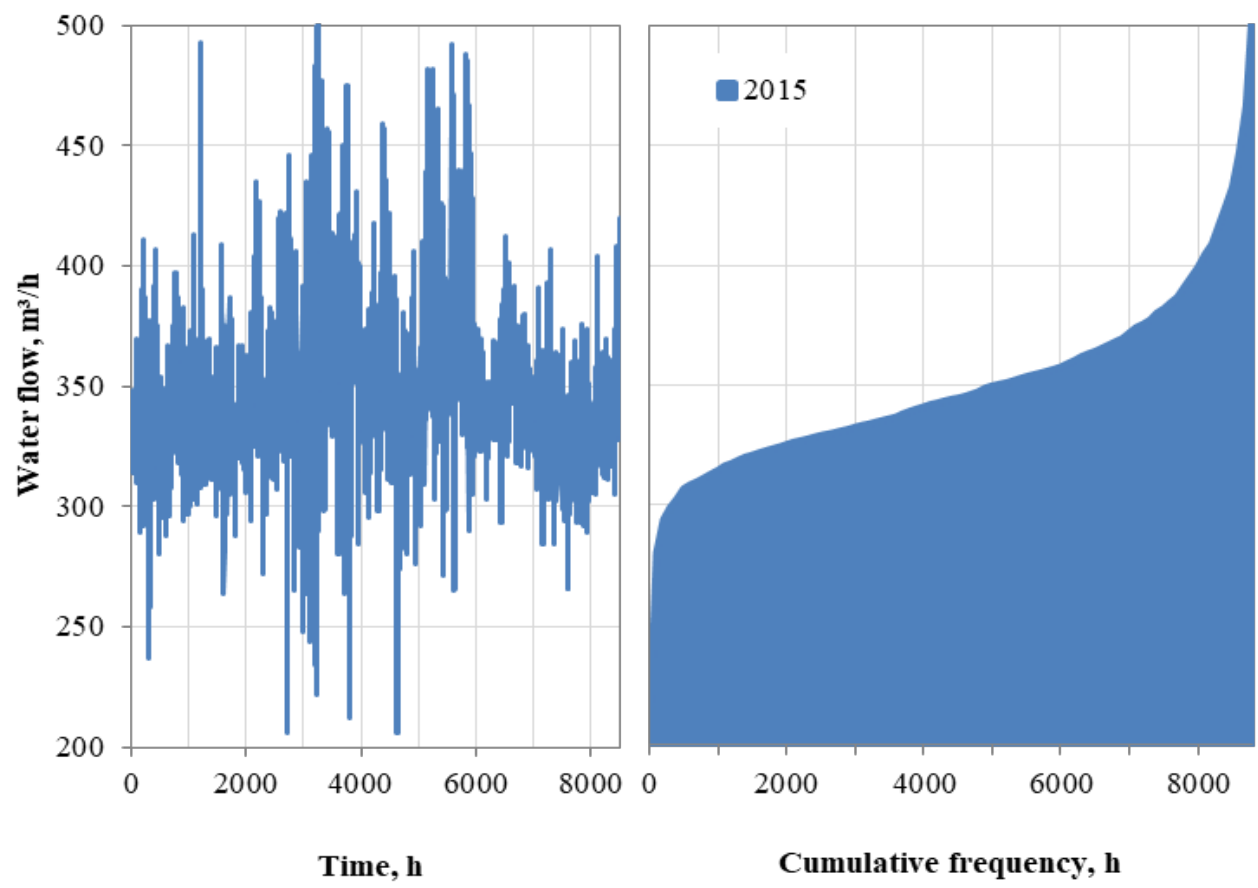

Fig. 3. Intake water flows ratio and its cumulative frequency in year 2015. 


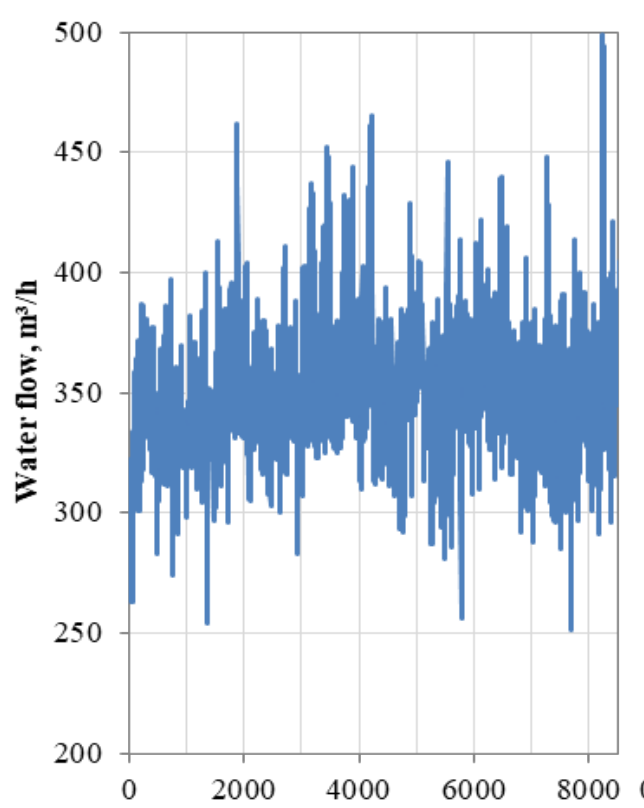

Time, h

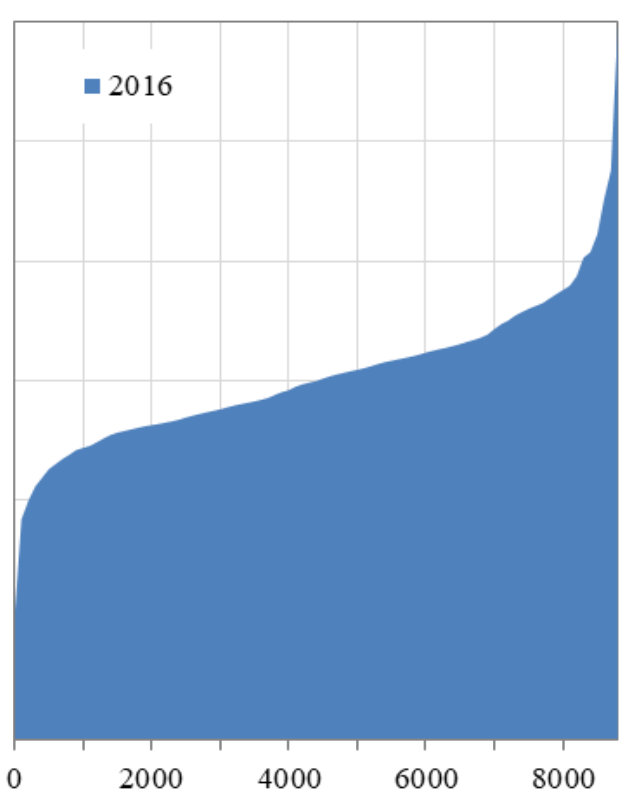

Cumulative frequency, $h$

Fig. 4. Intake water flows ratio and its cumulative frequency in year 2016.

In case of Głogów city the 2014-2016 data was taken (Fig. 2, 3 and 4). The full analysis covered 4 variants of HP nominal water flow and 3 variants of domestic water cooling level (temperature drop) for each year in the database (Fig. 5). In total, 36 mathematical model variants were considered.
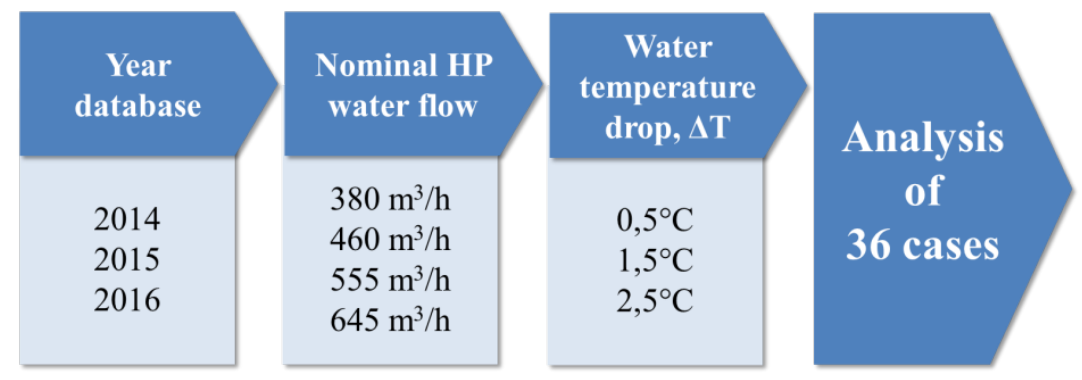

Fig. 5. Flow chart diagram of HP integration analysis cases.

Based on the flow statistics and HP technical data of one the leading large scale waterto-water HP manufacturer, five HP units thermal station was design in Głogów water intake. The analyzed cases require on the one hand applying by-pass as a protection against overflow and on the other hand using HP with minimal flow, which does not cause excessive quantities of emergency shutdown (Fig. 6). 
The following theses have been tested:

- the larger HP water flow, the more renewable heat supplied

- the greater domestic water cooling level, more renewable heat supplied

- the larger HP water flow, the greater risk of emergency shutdown.

The analysis included four nominal flows through 5 parallel connected HP by three different water temperature drop levels $\left(0,5 ; 1,5\right.$ and $\left.2,5^{\circ} \mathrm{C}\right)$ for years 2014,2015 and 2016. Using the statistical analysis of flow database, basic parameters of the domestic water network were determined, such as minimum and maximum flow in recent years (flow range), mean flow and standard deviation (which included the range of the majority of observations of the examined feature). Figure 6 shows results and general statistics for analyzed cases. Based on these results, four cases of HP nominal flow were analyzed: 380 , 460,555 and $645 \mathrm{~m}^{3} / \mathrm{h}$. The minimal, safe flows for 5 parallel connected HP units are: 206 , 250,300 and $350 \mathrm{~m}^{3} / \mathrm{h}$.

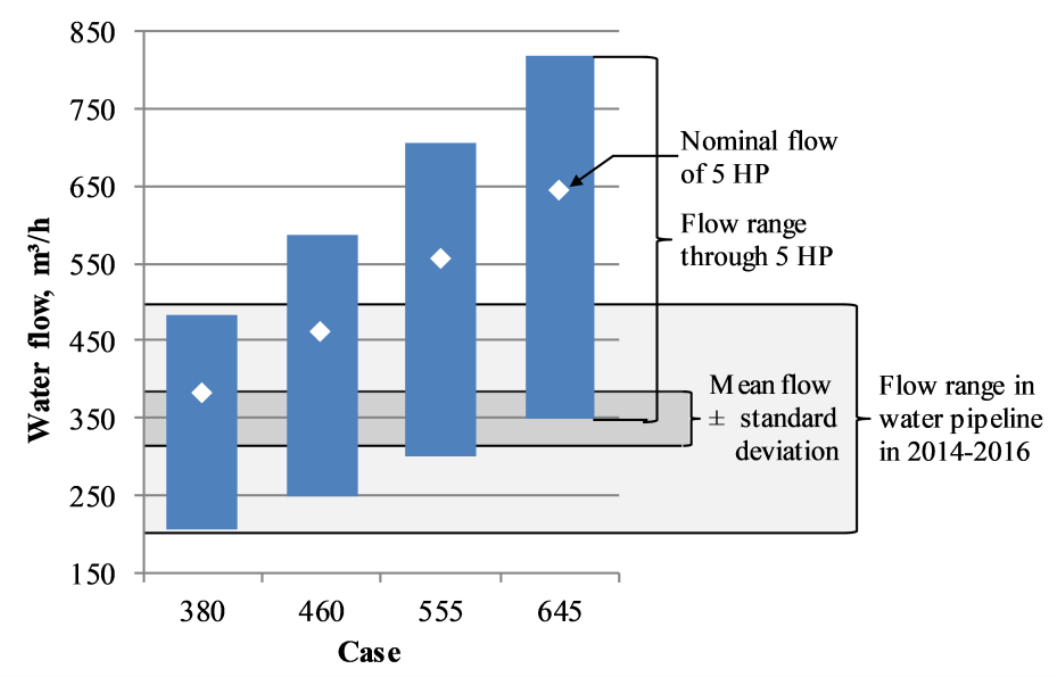

Fig. 6. Graphical analysis of the nominal flow of the HP based on the intakes statistical data.

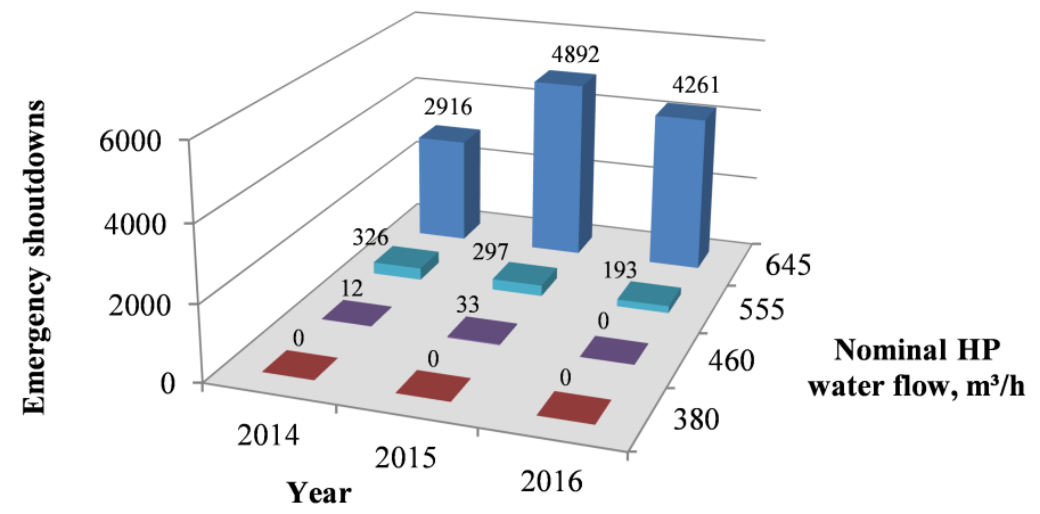

Fig. 7. The number of HP units emergency shutdowns in analyzed years and nominal HP water flows. 
The number of HP emergency shutdowns was calculated in a mathematical model, for the measured variable intake water flows, in each year and for 4 variants of the HP nominal water flows (Fig. 7). The $645 \mathrm{~m}^{3} / \mathrm{h}$ case has a huge, unacceptably high number of HP shutdowns and therefore was excluded from the next analysis. Reducing the HP nominal flow to 460 or 380 almost completely eliminates this phenomenon.

The seasonal performance of HP units is described by the SCOP factor. The SCOP for HP thermal station in Głogów was calculated for sink design temperatures $65 / 45^{\circ} \mathrm{C}$, suitable for supplying the own heating system and for supporting the city district heating (Fig. 8). Increasing the HP nominal water flow does not result in a proportional rise of SCOP, but causes the rapid enhance the risk of emergency shutdowns. A change in the HP nominal flow from 380 to $555 \mathrm{~m}^{3} / \mathrm{h}$ (by $46 \%$ ) results in a SCOP increase by only up to $3.9 \%$ and the emergency shutdowns also occurs.

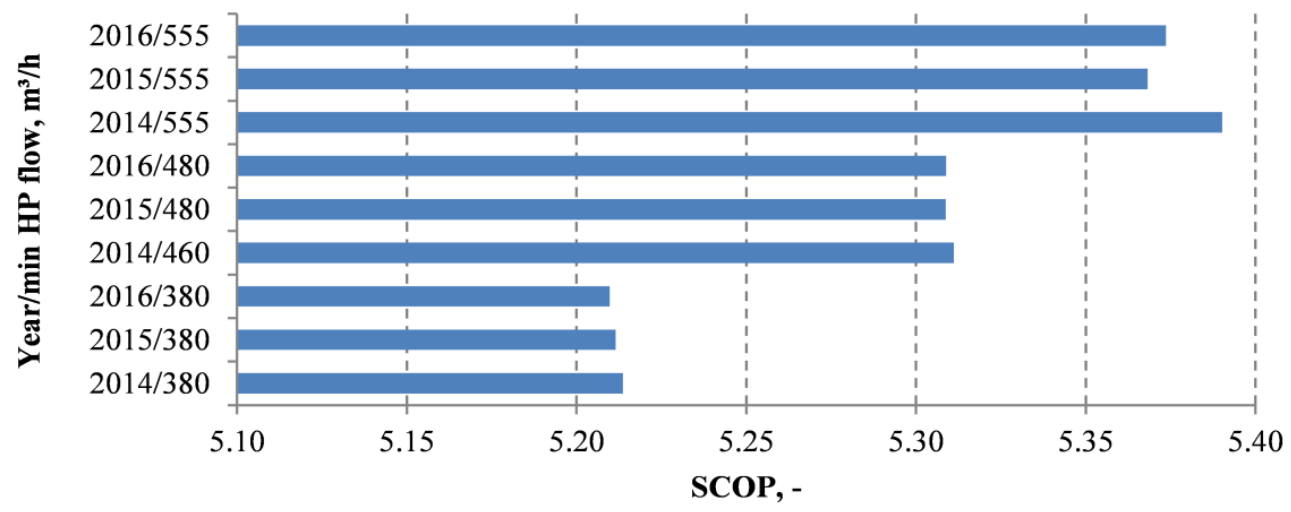

Fig. 8. The HP units SCOP factors of analyzed years and HP nominal water flows.

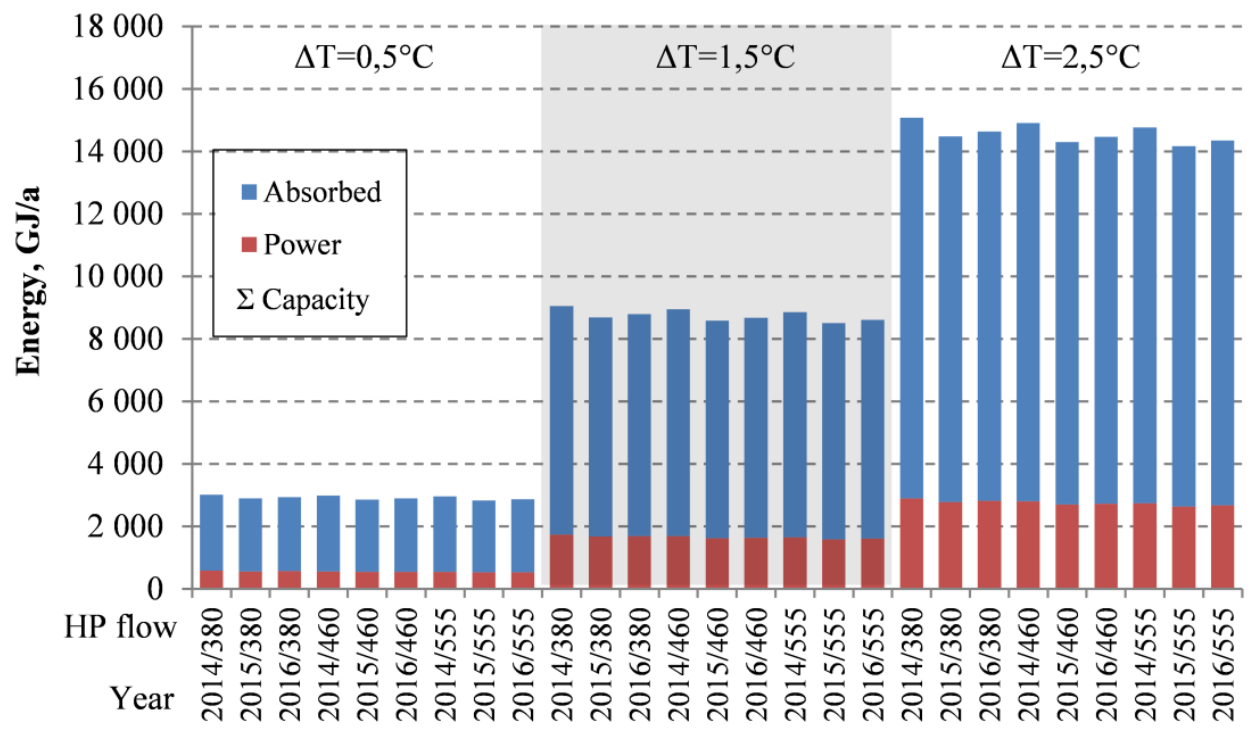

Fig. 9. Thermal energy supplied by HP units and its driving energy for analyzed water temperature drop, years and water flows. 
The SCOP of HP unit describes the amount of supplied heat and the quantity of consumed driving energy in working conditions. Fig. 9 presents the thermal energy supplied by HP units and its driving energy (electricity) for analyzed water temperature drop, years and water flows. It is evident, that the domestic water cooling level has a bigger impact on amount of thermal energy supplied by HP than an intake water flow increasing. By change the water cooling level from 0,5 to $2,5^{\circ} \mathrm{C}$ increases energy supplied up to $400,3 \%$.

\section{Conclusions}

The water-to-water, electrically driven HP technology enables to use the energy potential of water intakes and domestic water networks for generate of renewable heat. The variability of water intake flow causes the risk of HP unit emergency shutdown. For this reason the sizing of HP units and the selection of HP nominal water flow should be made individually and on base of long-term water flow measurement data. The increasing of HP nominal flow rapidly rise the HP emergency shutdown risk and slightly raises the SCOP. Much better effects of amount of thermal energy supplied by HP can be achieved by increasing the intake water cooling, of course with the risk of freezing.

It should be noted that the analysis of the HP selection on the basis of flow and temperature database should be a common procedure. The database for most cities is available for minimum several years due to the need to monitor the water treatment process. Observing extensive water supply networks also allows for big cities with surface intake to use significantly more water cooling and increase the energy potential due to re-heating in the extensive network.

\section{References}

1. A.M. De Pasquale, A. Giostri, M.C. Romano, P. Chiesa, T. Demeco, S. Tani, District heating by drinking water heat pump: Modelling and energy analysis of a case study in the city of Milan, Energy, Volume 118, 2017, Pages 246-263

2. Bank danych lokalnych, https://bdl.stat.gov.pl

3. Central Statistical Office, Energy consumption in households 2012 (2015)

4. J.A. Elías-Maxil, Jan Peter van der Hoek, Jan Hofman, Luuk Rietveld, Energy in the urban water cycle: Actions to reduce the total expenditure of fossil fuels with emphasis on heat reclamation from urban water, Renewable and Sustainable Energy Reviews, Volume 30, 2014, Pages 808-820

5. https://www.pwik.glogow.pl/ 